\title{
BREEDING OF ORIENTAL PIED HORNBILL (ANTHRACOCEROS ALBIROSTRIS) IN CAPTIVITY AT SAYAJI BAUG ZOO, VADODARA, GUJARAT
}

\author{
Raju Vyas
}

Zoo Inspector, Sayaji Baug Zoo, Vadodara, Gujarat 390018, India.

\begin{abstract}
This is a first record of breeding success of Oriental Pied Hornbill (Anthracoceros albirostris) in captive condition at Sayaji Baug Zoo, Vadodara, Gujarat, India. A total of four chicks were born from 1996 to 2000. Average days of incubation and confinement of female were 37 days and 96 days respectively.
\end{abstract}

\section{Keywords \\ Oriental Pied Hornbill, Anthracoceros albirostris, breeding, captivity, Sayaji Baug Zoo, Gujarat}

\section{Introduction}

Hornbills (Bucerotidae and Bucorvidae) are distributed throughout in savannah and rain forests of the tropical regions of Africa, Asia and Australasia. There are 54 species of hornbills in the world (Kemp, 1979), ten of which occur in India. Hornbills are classified as climax species according to their place in biotic succession and as classic species according to their method of nesting (female plasters herself in directly in a natural cavity without modifying it). They need undisturbed, intact forest habitat to identify nest sites. Thus, the characteristics as well as the community structure of vegetation of the hornbill's nest habitat are important (Collias \& Collias, 1984).

Today, most of the species survive under anthropogenic pressure and some of the hornbill species have been drastically reduced due to extensive destruction and alteration of habitat and illegal hunting. These have affected breeding performance of hornbills which has gradually had an impact on their population.

Oriental Pied Hornbill (Anthracoceros albirostris) (= Anthracoceros malabaricus) is distributed from India (in India from Punjab (Kalesar) and Siwalik Range of Kumaon to eastern India and further in south in eastern Andhra Pradesh), to Nepal, Bhutan, southeastern China, Indochina, Myanmar and up to Thailand (Ali \& Ripley, 1987; Poonswad, 1993). It is noticed that the species is locally extinct in some forest pockets and the population has reduced to very low numbers in many areas. Deforestation and indiscriminate felling of trees have reduced its preferred habitats thereby drastically reducing availability of their specialized food and breeding requirements. There is an urgent need for conservation of this endangered species, if necessary, even by captive breeding.

Published literature on captive breeding of hornbills is very scarce, especially of Indian Bucerotidae. Some information on captive breeding of Buceros bicornis (Preuss \& Preuss, 1973; Choy, 1980; Golding \& Williams, 1986). First captive breeding of A. albirostris was attempted at Woodland Park, USA (Hutchins, 1976) and Sepahijala Zoo, Tripura (Das, 1998) and recently its subspecies Southern Pied Hornbill (A. a. convexus) was successfully bred at Chessington World of Adventures, UK (Ellis, 2000). The breeding ecology of the species was studied in the natural state in Tailand by Poonswad et al. (1997) and Frith and Douglas (1978).

\section{Materials}

Successful breeding of Oriental Pied Hornbill was attempted at the Sayaji Baug Zoo, Vadodara, Gujarat, from 1996-2000. Three hornbills were procured from a private bird dealer in the month of June 1986. All the three birds were kept in a cage in the aviary of the zoo (one female was lost in 1988, only a male and a female remained in the cage).

\section{Breeding enclosure}

The cage of the hornbills was $330 \times 380 \times 255 \mathrm{~cm}$ with two chambers. An inner chamber was enclosed with cement concrete wall and an outer chamber was enclosed with $1 \mathrm{x} 1 \mathrm{~cm}$ wire mesh. The top of the cage was covered with wire netting along with tiles. The cage was furnished with two dry multi-forked wooden branches (one in the inner chamber and the second at a slightly lower height in the outer chamber) for perching. A $120 \mathrm{~cm}$ high platform for artificial nesting was also provided. A large $(75 \mathrm{x}$ $40 \mathrm{~cm}$ ) cement barrel was provided for nesting. The $32 \mathrm{~cm}$ opening of the barrel was covered with a wooden lid, that had a $12 \mathrm{~cm}$ 
wide slit in the middle for entrance to the barrel cavities.

An observation hole was bored in the back wall of the cage opposite the artificial nest for observation. All nesting activities of the hornbills were observed from this hole.

Different types of ripe fruits and small animals (Table 1) were offered ad libitum to the pair daily at fixed times and twice a day during the breeding periods of February to July. Feeding and related behavioural activities were recorded as described by Mukherjee et al. (1996). Suitable arrangements were made to prevent visitors from disturbing the breeding pair from February to July.

Table 1. Food items offerred to captive Oriental Pied Hornbill at Sayaji Baug Zoo, Vadodara

\begin{tabular}{ll}
\hline Food items & \\
\hline Grapes & Bread and milk \\
Banana (Musa paradisiacal) & Boiled eggs \\
Papaya (Carica papaya) & Brook's Gecko (Hemidactylus brookil) \\
Apple & House Gecko (H. flaviviridis) \\
Chikoo (Manilkara zapota) & Garden Lizard (Calotes versicolor) \\
Jamun (Syzygium cumini) & \\
\hline
\end{tabular}

\section{Breeding behaviour}

During February 1992 and 1993, it was noticed that the pair was active and very vocal. An earthen pot ( 40 x 40 with entrance of $12 \mathrm{~cm}$ ) was provided for nesting. Further no activity was noticed in the pair, except that of the male was feeding the female.

In January 1994, the zoo authority again provided a 40 x $60 \mathrm{~cm}$ hollow wooden log. Both birds were more active than they were in 1993. The male frequently offered food to the female during the first week of March. Both the birds inspected the hollow cavity of the log. In the second week of March the female started to plaster the entrance with the help of food and other materials. She sealed the entrance completely from the outside. No specific behaviour was noticed in the year.

In the early month of 1996, a cement barrel was provided in the cage of hornbills, as artificial nest cavity and a large chunk of wet clay as stimulus for sealing the nest entrance. Both birds were very active. During morning hours, both were very vocal and hopping from branch to branch and on the barrel. The male offered food to the female frequently. The male vocalised loudly with stretched neck with beak upward, after the acceptance of food by the female. Bill-locking behaviour was observed very frequently in March. During this year the hornbills bred and the female successfully reared two chicks. After this event, the pair continued to breed for four years from 1996 to 2000 .

\section{Courtship and mating}

During the year 1996, courtship-feeding behaviour was recorded first the time in the month of March. The artificial nest was provided to the birds based on this behaviour. The pair was also seen interlocking bills without feeding, an activity resembling 'billing behaviour' in other species, which resulted in copulation for the first time on 15 March 1996 at $1617 \mathrm{hr}$ and prior to two days of plastering activities and about 14 days before she was enclosed. Intensive courtship behaviour like offering food, interlocking bills and loud vocalization was observed almost 4 to 14 days prior to her going into confinement for incubation.

The first observed copulation at $1617 \mathrm{hr}$ occurred on a branch, the female leaning forward and the male mounting for about 4-7 second. The male produced a very loud cackling vocalization before and immediately after the successful mating.

\section{Nest plastering and plastering materials}

The male and female inspected the nest cavity before beginning the courtship behaviour. As soon as the courtship behaviour started the female started to plaster the entrance with the help of the male. It was observed that male brought food, sat in front of the nest and extended his head into the interior of the nest. When the female approached he would move away from the entrance to allow her access to the nest. As soon she was inside, the male began to regurgitate food with quick downward thrusts of his head. Earlier, the female sat outside and plastered the entrance with layers of plaster material in such a way that allowed her to enter into the cavity. Finally, she entered the nest 6-8 hours before confinement. On the last day the male brought plastering materials and covered the entrance to leave a vertical slit through which the male could insert his bill only.

The material was plastered on to the nest entrance with rapid sideways motion of the bill, the flat lateral surfaces of which were used as hammer. The plaster materials used by the birds was regurgitated foods, mud, fine sand, faeces, clay and small feathers.

\section{Female's confinement}

The female's confinement was first recorded on 30 March 1996 at $1500 \mathrm{hr}$ and lasted up to the morning of 30 June, for 91 days. The average time of confinement for the period 1996-2000 recorded was 96.66 days with a minimum of 90 and maximum of 109 days. The female was in confinement for 69 and 82 days only in 1998 and 1999 respectively, may be due to some disturbance or threat from snakes (which are usually found in the aviary).

The female sat in the nest usually facing the entrance while incubating. She would stand, turn and press her posterior close to the opening of the nest to excrete. 
The female was fed by the male during the entire period of her confinement. Whenever a live calotes or gecko was offered to him, he caught it and immediately offered it to the female. Sometimes, he consumed the lizard and fed her after a 10-30 minutes by regurgitation.

\section{Clutch size, incubation period and breeding successes}

First sound of chicks was heard on the morning of 6 May 1996, after 35 days of female confinement in the nest. She came out on 30 June 1996, with two chicks. The incubation period was considered from the day of imprisonment to the hearing of chick sound from the nest. The total average incubation period was 37 days.

During 1996 and 1997, four chicks were born of which one died. In 1998 and 1999 the female came out earlier than usual from the nest without any chick. In both these years the chick was heard and its movements were observed but due to some unknown reason they did not survive, neither was the corpse or any evidence found in the nest. One chick only survived during 2000. Four chicks were raised successfully from the five breeding seasons from 1996 to 2000, with annual breeding success of $60 \%$ (total numbers of success attempts/total numbers of attempts) as recorded during this study.

\section{Young hornbill}

At $0700 \mathrm{hr}$ on $30 \mathrm{June} 1996$, the first young hornbill was observed out of the nest along with its mother. Nestlings were very similar in appearance to the adult, except for the casque, bill, and iris colour. The less developed bill and casque was ivory-yellow without the black areas present in the adult. The iris was white in both the young birds, but the male's iris was a little larger. Average fledgling period was 59 (range 51-71) days.

\section{Moult of the female}

It was noticed that the female came out from confinement along with the chicks, with a dirty bill and body feathers, and appeared under-nourished. Every year we collected a number of moulted wing and tail feathers from the nest after she came out of the cavity (Table 2), which indicated the she moulted during her confinement.

\section{Discussion}

The present observation of courtship behaviours like offering food, interlocking of bills and loud vocalization are quite similar to the behaviour recorded by Hutchins (1976) for this species. The recorded breeding season of the species in this study from during March to June is also similar to the observations by Hutchins (1976) in captivity and it is a little delayed than that recorded by Poonswad et al. (1987) in wild birds in Thailand.

The plastering behaviour of the species is quite similar to that found in other species of Bucerotidae. Present incubation period of 37 days is eight days longer than the 29 days recorded by (Hutchins, 1976) and 25-27 days recorded by Poonswad et al. (1987) because here incubation period was considered from the day of confinement of the female to the hearing of chick sound from the nest. According to Hutchins (1976), captive female laid eggs after 5-7 days of enclosing herself in the nest. Hence, the fledgling period of 59 days observed in present study is quite close to fledgling period of 55 days of Hutchins (1976) study.

Moulting in female during her confinement was assumed by the presence of a large numbers of wing and tail feathers in the nest. However, Hutchins (1976) interpreted the large numbers of wing and tail feathers in the nest due to frequent preening and cleaning by female. Stonor (1937) has suggested that the reduction in light stimulates the pituitary to trigger the moulting process. Feathers are used for lining the nest in several species of birds. Here it is interpreted as moulting on the basis of present study.

Present study indicates that breeding of hornbills in ex situ condition is not difficult, if the essential needs are met. The breeding enclosure, artificial nest box and its size are critical

Table 2. Summary of breeding data of Oriental Pied Hornbill (A. albirostris) at Sayaji Baug Zoo.

\begin{tabular}{|c|c|c|c|c|c|c|}
\hline $\begin{array}{l}\text { Mating } \\
\text { observed }\end{array}$ & $\begin{array}{l}\text { Female } \\
\text { sealed }\end{array}$ & $\begin{array}{l}\text { Chick first } \\
\text { heard }\end{array}$ & $\begin{array}{l}\text { Female out of } \\
\text { confinement }\end{array}$ & $\begin{array}{l}\text { Total days in } \\
\text { confinement }\end{array}$ & $\begin{array}{l}\text { Successful } \\
\text { hatchlings }\end{array}$ & $\begin{array}{l}\text { Feathers found } \\
\text { in the nest }\end{array}$ \\
\hline 15.iii.1996 & 30.iii.1996 & 6.v.1996 & 30.vi.1996 & 92 & $2(1 M+1 F)$ & 8 \\
\hline \multicolumn{7}{|l|}{ 6.iii.1997 } \\
\hline 9.iii.1997 & 13.iii.1997 & 1.iv.1997 & 30.vi.1997 & 109 & $1(F)$ & 12 \\
\hline 14.iii.1998 & 22.iii.1998 & 20.iv.1998 & 30.v.1998 & 69 & * & 10 \\
\hline- & 18.iii.1999 & - & 09.vi.1999 & 82 & * & 32 \\
\hline 7.iii.2002 & 22.iii.2000 & 29.iv.2000 & 19.vi.2000 & 90 & $1(F)$ & 21 \\
\hline
\end{tabular}

* chick died 
factors. Providing plastering materials like soft clay and food items to the species work as stimulus for breeding.

\section{Acknowledgement}

I thank Mr. V.A. Jadeja, Curator, Sayaji Baug Zoo, Vadodara for providing facilities during the study. Also thanks to Mr. M.J. Kachela, Zoo Inspector and Mr. Poonam Budha, Animal Keeper for providing information and continued support in the study. I am very thankful to Dr. B.M. Parasharya, Anand for reading early drafts and some of the useful and valuable suggestions and comments on the manuscript.

\section{References}

Ali, S. and S.D. Ripley (1987). Compact Handbook of the Birds of India and Pakistan. Oxford University Press, Delhi, 737pp.

Choy, P.K. (1980). Breeding the Great Indian Hornbill (Buceros bicornis) at Jurong Bird Park. International Zoo YearBook 20:204-206. Collias, N.E. and E.C. Collias (1984). Nest building and bird behaviour. Princeton University Press, Princeton, 250pp.

Das, S. (1998). News: Sepahijala Zoo. Zoos' Print 13(10): 42.

Ellis, J.A. (2000). Breeding the Southern Pied Hornbill at Chessington World of Adventures, Surry-England (http:/www. sefibills.com).

Firth, C.D. and V.E. Douglas (1978). Notes on ten Asian hornbill species (Aves: Bucerotidae); with particular reference to growth and behaviour. Natural History Bulletin of Siamese Society 27: 35-82.
Golding, R.R. and M.G. Williams (1986). Breeding the Great Indian Hornbill (Buceros bicornis) at Cotswald Wildlife Park. International Zoo YearBook 24/25: 248-252.

Hutchins, M. (1976). Breeding biology and behaviour of the Indian Pied Hornbill (Anthracoceros m. malabaricus). International Zoo YearBook 16: 99-104.

Kemp, A.C. (1979). A review of the hornbills: biology and radiation. Living Bird 17: 105-136.

Mukherjee, A., S. Sapana, G.S. Padate, K. Kachhela and V. Jadeja. (1996). Indian Pied Hornbill Anthracocerus malabaricus breeding in captivity. Salim Ali Birth Centenary Celebrations (9-16 November 1996), Pan-Asian Ornithological Congress and XII Bird Life Asia Conference, Coimbatore, India. Abstracts: 96-97.

Poonswad, P.A. (1993). Identification of Asian hornbills: 26-33. In: Poonswad P. and A.C. Kemp (Editors). Manual to the Conservation of Asian Hornbills. The Asia Foundation, 211pp.

Poonswad, P., A. Tsuji and C. Ngampongsai. (1987). A comparative study on breeding biology of sympatric hornbill species (Bucerotidae) in Thailand with implications for breeding in captivity. Symposium on breeding birds in captivity.

Preuss, M. and B. Preuss (1973). The breeding of "Double Horn Bird" (Buceros bicornis) Linn., 1758 in the Rostock Zoo. Der Zoologische Garten 4392/3: 65-73.

Stonor, C.R. (1937). On the attempted breeding of a pair of Trumpeter Hornbill (Byeanistes buceinator) in the Gardens in 1936: together with some remarks on the physiology of the moult in the female. Proceedings of the Zoological Society of London 107(A): 89-94.

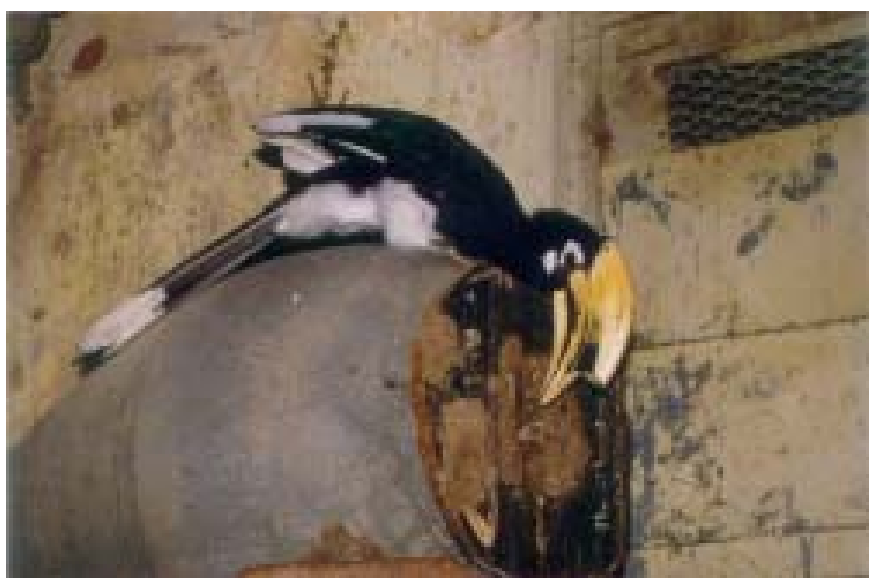

Male feeding the female in the barrel-nest.

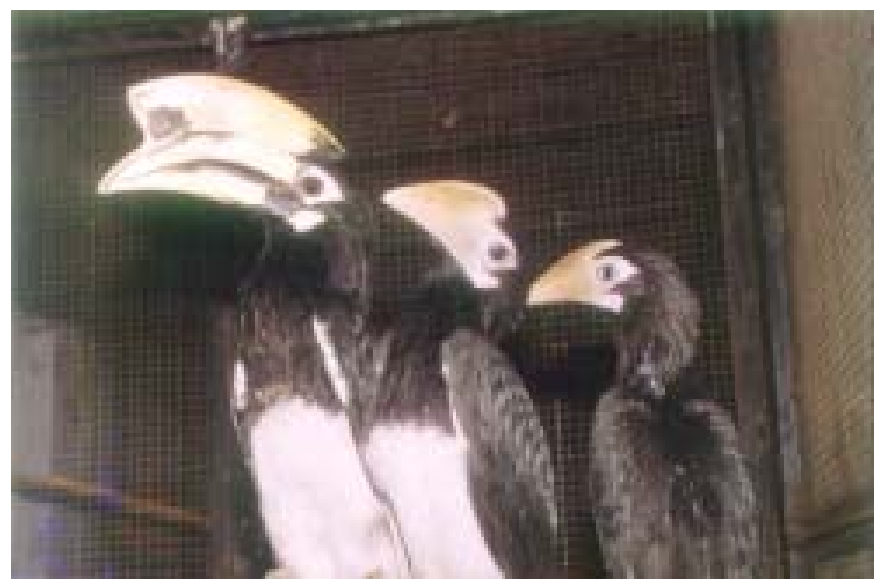

Young hornbills (1996 batch) with father. 